\begin{tabular}{|c|c|c|c|c|c|}
\hline MRI Lesion & "All slice" & Central 5 slices & Peripheral slices & $\begin{array}{l}\mathrm{P} \text { value central vs } \\
\text { peripheral slices }\end{array}$ & $\begin{array}{c}\text { P value } \\
\text { "all slice" vs } \\
\text { central slices }\end{array}$ \\
\hline \multicolumn{6}{|c|}{ Mean (SD) Lesion Score Per Case } \\
\hline Erosion & $2.4(4.5)(0-22.9)$ & $1.8(3.4)(0-17.1)$ & $0.6(1.4)(0-10.1)$ & $<0.001$ & $<0.001$ \\
\hline Fat lesion & $2.5(5.9)(0-34.0)$ & $1.8(4.5)(0-25.1)$ & $0.7(1.8)(0-9.9)$ & $<0.001$ & $<0.001$ \\
\hline Sclerosis & $2.0(4.9)(0-39.0)$ & $1.5(3.6)(0-26.1)$ & $0.5(1.5)(0-12.9)$ & $<0.001$ & $<0.001$ \\
\hline Backfill & $0.5(1.5)(0-12)$ & $0.4(1.2)(0.0-9.3)$ & $0.1(0.4)(0-2.7)$ & $<0.001$ & 0.84 \\
\hline Ankylosis & $0.5(3.4)(0-30.7)$ & $0.3(2.3)(0-20.0)$ & $0.2(1.2)(0-11.3)$ & 0.10 & 0.18 \\
\hline \multicolumn{6}{|c|}{$\begin{array}{l}\text { Mean (SD) (Range) \% of Total Lesion Score in Central vs } \\
\text { Peripheral slices }\end{array}$} \\
\hline Erosion & $100 \%$ & $76.4 \%(28.9 \%)(0-100 \%)$ & $23.6 \%(28.9 \%)(0-100 \%)$ & $<0.001$ & NA \\
\hline Fat lesion & $100 \%$ & $75.4 \%(26.5 \%)(0-100 \%)$ & $24.6 \%(26.5 \%)(0-100 \%)$ & $<0.001$ & NA \\
\hline Sclerosis & $100 \%$ & $79.5 \%(22.9 \%)(0-100 \%)$ & $20.5 \%(22.9 \%)(0-100 \%)$ & $<0.001$ & NA \\
\hline Backfill & $100 \%$ & $86.0 \%(20.2 \%)(0-100 \%)$ & $\begin{array}{c}14.0 \%(20.2 \%) \\
(0-100 \%)\end{array}$ & $<0.001$ & NA \\
\hline Ankylosis & $100 \%$ & $59.0 \%(36.4 \%)(0-100 \%)$ & $41.0 \%(36.4 \%)(0-100 \%)$ & 0.56 & NA \\
\hline \multicolumn{6}{|c|}{ ICC of 7 readers (Mean (SD) (Range)) } \\
\hline MRI lesion & All slices & \multicolumn{2}{|c|}{ Central 5 slices } & \multicolumn{2}{|c|}{ Peripheral slices } \\
\hline Erosion & $0.54(0.15)(0.28-0.84)$ & \multicolumn{2}{|c|}{$0.58(0.13)(0.34-0.85)$} & \multicolumn{2}{|c|}{$0.40(0.17)(0.10-0.66)$} \\
\hline Fat lesion & $0.61(0.18)(0.30-0.89)$ & \multicolumn{2}{|c|}{$0.63(0.16)(0.35-0.88)$} & \multicolumn{2}{|c|}{$0.52(0.20)(0.19-0.82)$} \\
\hline Sclerosis & $0.73(0.18)(0.36-0.94)$ & \multicolumn{2}{|c|}{$0.73(0.16)(0.36-0.91)$} & \multirow{2}{*}{\multicolumn{2}{|c|}{$0.67(0.19)(0.27-0.94)$}} \\
\hline Backfill & $0.37(0.21)(0.10-0.85)$ & \multicolumn{2}{|c|}{$0.39(0.19)(0.14-0.83)$} & & \\
\hline Ankylosis & $0.97(0.02)(0.91-0.99)$ & \multicolumn{2}{|c|}{$0.99(0.01)(0.97-1.0)$} & \multicolumn{2}{|c|}{$\begin{array}{c}0.18(0.23)(0.0-0.80) \\
0.85(0.10)(0.62-0.98)\end{array}$} \\
\hline
\end{tabular}

\section{POS0033 IN RADIOGRAPHIC AXIAL SPONDYLOARTHRITIS, BRIDGING SYNDESMOPHYTES INCREASE RISK OF FACET JOINT ANKYLOSIS ON THE SAME VERTEBRAL LEVEL WHILE FACET JOINT ANKYLOSIS DOES NOT INCREASE RISK OF SAME LEVEL SYNDESMOPHYTES}

R. Stal ${ }^{1}$, A. Sepriano ${ }^{1}$, F. A. Van Gaalen ${ }^{1}$, X. Baraliakos ${ }^{2}$, R. Van den Berg $^{1}$, M. Reijnierse ${ }^{3}$, J. Braun ${ }^{2}$, R. B. M. Landewé ${ }^{4}$, D. Van der Heijde ${ }^{1}$. ${ }^{1}$ Leiden University Medical Center, Rheumatology, Leiden, Netherlands; ${ }^{2}$ Rheumazentrum Ruhrgebiet, Rheumatology, Herne, Germany; ${ }^{3}$ Leiden University Medical Center, Radiology, Leiden, Netherlands; ${ }^{4}$ Amsterdam University Medical Center, Rheumatology, Amsterdam, Netherlands

Background: In radiographic axial spondyloarthritis (r-axSpA), spinal damage manifests as syndesmophytes and facet joint ankylosis (FJA).

Objectives: Explore whether syndesmophytes and FJA seem to have a preferential order of development.

Methods: Data were used from the Sensitive Imaging in Ankylosing Spondylitis cohort from Leiden and Herne. Patients underwent low-dose Computed Tomography (IdCT) at baseline and two-years. LdCT images were scored independently by two trained readers. Vertebrae were scored according to the Computed Tomography Syndesmophyte Score (CTSS) for presence and size of syndesmophytes; facet joints were scored as not-ankylosed and ankylosed. Analyses were performed on the vertebral unit (VU) level and using individual-reader data (Figure 1). Two hypotheses were tested: 1) presence of bridging syndesmophyte(s) is associated with FJA on the same VU two years later, and 2) presence of FJA is associated with syndesmophyte(s) on the same VU two years later. Generalized Estimating Equations (GEE) models were used to take into account the correlations between VUs from the same patient and adjusting for reader to account for individual reader scores. Two models were tested per hypothesis using different outcomes. Model 1 uses the presence of syndesmophytes or FJA as outcome adjusting for the outcome at baseline. Model 2 uses development of new syndesmophytes or FJA at two years plus an increase in the number of syndesmophytes or FJA.Results: In total, 50 patients were included (mean age $49,84 \%$ male, $82 \%$ HLA-B27+). At baseline, there was a higher percentage of bridging syndesmophytes (range: $10-60 \%$ ) than FJA (range: 8-36\%) considering all VUs and both readers (Figure 1). In both models, presence of bridging syndesmophytes was associated with development of FJA two years later $(\mathrm{OR}(95 \% \mathrm{Cl})$ Model 1: 3.35 (2.18-5.14); Model 2: 2.23 (1.19-4.16)) while presence of FJA at baseline did not have a statistically significant association with development of syndesmophytes two years later (Table 1).

Conclusion: The data showed a higher occurrence of bridging syndesmophytes than FJA at baseline and showed significantly increased odds to develop FJA when bridging syndesmophyte(s) are present on the same VU two years prior. This mechanism did not hold true for the other direction. These results cautiously imply that bridging syndesmophytes precede FJA, rather than FJA preceding syndesmophytes.

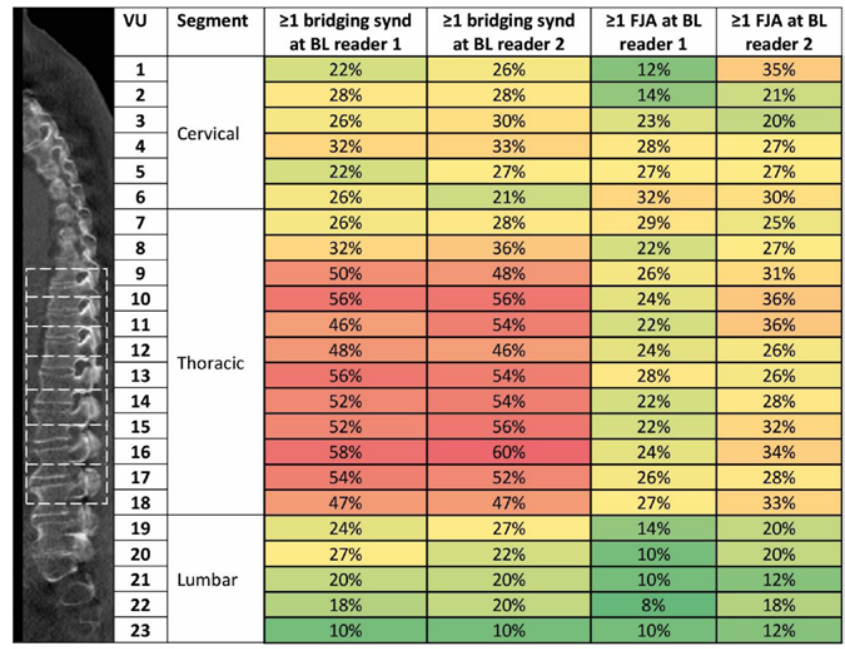

Figure 1. Percentage of occurrence of syndesmophytes and facet joint ankylosis per vertebral unit and per reader at baseline.

Figure 1 displaying percentages of patients with a bridging syndesmophyte and with facet joint ankylosis at baseline, per reader. The image on the left illustrates the vertebral unit level (VU) at which analyses were performed. Seven VUs are illustrated in dashed boxes as example. Synd, syndesmophyte; FJA, facet joint ankylosis; BL, baseline.

Table 1. Associations between facet joint ankylosis and syndesmophytes

\begin{tabular}{lcc}
\hline & $\begin{array}{c}\text { Model 1: development } \\
\text { of new FJA/syndesmo- } \\
\text { phytes at FU } \\
\text { OR }(95 \% \mathrm{Cl})\end{array}$ & $\begin{array}{c}\text { Model 2: development and/ } \\
\text { or increase FJA/syndesmo- } \\
\text { phytes at FU } \\
\text { OR }(95 \% \mathrm{Cl})\end{array}$ \\
\hline $\begin{array}{l}\text { Hypothesis 1 } \\
\text { Presence bridging syndesmophytes at } \\
\text { BL on development of FJA at FU }\end{array}$ & $\mathbf{3 . 3 5}(\mathbf{2 . 1 8 - 5 . 1 4 )}$ & $\mathbf{2 . 2 3}(\mathbf{1 . 1 9 - 4 . 1 6 )}$ \\
$\begin{array}{l}\text { Hypothesis 2 } \\
\text { Presence FJA at BL on development of } \\
\text { syndesmophytes at FU }\end{array}$ & $1.60(0.88-2.91)$ & $1.12(0.76-1.66)$ \\
\hline
\end{tabular}

Disclosure of Interests: None declared.

DOI: 10.1136/annrheumdis-2021-eular.1097 